\title{
Translocal Circulation: Place and Subjectivity in an Extended Filipino Community
}

As migration and mobility produce new subject positions, they transform and extend locality and create both new subjective experiences of place and new subjectivities. This paper explores the culture of circulation that emerges between a migrant sending village in the Philippines and Hong Kong, as it is created through the mobility of female contract workers.

Keywords: Labour Migration, Mobility, Locality, Philippines, Hong Kong, Globalisation

In the 1990s, globalisation was promoted as a 'culture' that the Philippine population was exhorted to 'imbibe and expand' (Kelly 2000, p.1). Expansion of this culture occurred most spectacularly through accelerating Filipino participation in the global labour force. Integrated into global markets for unskilled domestic labour since the 1970s, the Philippines now has the largest flows of overseas migrant workers in the global economy (Tyner \& Donaldson 1999, p. 1) and the largest per capita number of female workers overseas (Boyle 2002). Recent government estimates placed 7,402,894 workers overseas from a population of approximately eighty million (POEA 2004). Of these emigrants, 2,736,528 were permanent emigrants, 3,099,940 were on temporary contracts abroad and 1,566,426 were classified as 'irregular', meaning they were either working on tourist visas or were illegal residents overseas (POEA 2004). In 2003, the government recorded $69 \%$ of the newly hired overseas contract workers leaving the Philippines as female. In that same year, a total of (US\$) 6,345,815 was remitted to the Philippines from land-based overseas workers (POEA 2004). More recent estimates place one tenth of the population overseas and 30 per cent of households 'subsisting on remittances' (Bello 2005). Monies remitted back into the nation from contract workers and outmigrants have a huge impact on the domestic economy in the Philippines. Remittances are generally thought to be equivalent to the annual interest payable on the nation's sizeable foreign debt (Rodriguez 1998; Puri \& Ritzema 1999) and popularly understood to be the financial lifeline saving the Philippines from financial collapse. Such global flows of remittances are increasing in importance in the world economy. The Inter-American Development Bank recently estimated that the 200 billion (US) per year sent by migrants around the world now outstrips both foreign direct investment and overseas development assistance (Bello 2005). Thus the culture of circulation produced through the mobility of migrants has become a defining feature of contemporary Philippine localities and simultaneously of the global economy. 
At the level of the local and everyday, the global flow of labour makes the absent presence of female workers a definitive part of the texture of Filipino life. Flows of female labour migrants are dominated by women who are typically single, comparatively well educated and, at first departure from the Philippines, in their early twenties (Lan 2003). Their long periods of absence and the monies they send home reshape both landscapes and the sense of place in their sending communities by providing resources for agriculture, housing and education and introducing new technologies of communication (McKay 2005.) Though their mobility is transnational, the transformations arising from individual migration are fundamentally experienced as local and personal, with the links migrants create between home and away mediated at the household and village level. Migrant women create new social networks that pair specific sending places with receiving neighbourhoods through highly personalised relations (see Pertierra et al. 1992; Pertierra 2001). Practices of communication and remittance connect migrants' relations with overseas employers, credit providers and romantic interests with changes enabled by migrant earnings remitted home - new forms of housing, crops, livelihood activities and the goods received as gifts by kin and consociates. The value and knowledge circulating through these highly personal, intimate, and simultaneously global networks change the texture of 'place' in the Philippines.

During research visits in rural Philippine villages (2003 and 2005), I found respondents would identify places having lots of overseas workers abroad as 'progressive'. Progress, in their terms, was made visible both through intensified patterns of consumption and enhanced local and national mobility, especially via transport and communications technologies. People receiving remittances had better houses and clothes, did less agricultural labour and could afford to own their own means of transport and communication - cars and mobile phones. A tower indicating mobile phone network coverage was pointed out to me as a key indicator of remittance-led development. Because local ability to mobilise monies from overseas and global networks now depends in large part on new communications technologies - mobile phones, email and satellite phones - the more easily a village can contact its absent workers, the more easily people can appropriate, redistribute and invest migrant earnings. While the popular enthusiasm for the mobile phone has enabled Filipinos to generate a virtual world consisting of imaginary geographies with their corresponding cultures and social relationships (Pertierra et al. 2002, p. 8), it is also clear that, by linking villages to expatriate workers overseas, the mobile phone network has also created perhaps more prosaic, but no less radically place-altering, enhancements in trade relations and household communication.

Academic interest in the impacts of these new communications technologies is relatively new, but studies to date suggest that such technologies do not appear to 'fracture' localities, but to extend some while creating others de novo. Improved communication has enabled many Filipino households to extend social and economic networks between several nations. A classic example of 
this extension of locality appears in Nicole Constable's (2003a, 2003b) ethnography of Filipinas in internet-mediated international marriages. Constable (2003b, p. 32) finds that the purported power of the electronic medium has not transcended subjects' agency within it, arguing that 'the internet has turned correspondence into more than a method of introduction and into a community in the larger sense'. We can imagine that such virtual efforts at place-making overlap, intertwine, and are layered on top of place-based, face-to-face localities. Locality production emerges as one of many processes and locality as one of many institutions, including state agencies, NGOs, and religious organisations that interpellate individuals as members of social groups or bearers of culture. Mobile people, such as migrant workers, participate in multiple localities. Constable's respondents, for example, participate in local socialities in Manila, their sending villages, Hong Kong and the United States.

Here I explore migrant circulation from a single sending community, examining the reworking and persistence of locality. My argument examines the social relations that comprise circulation between a migrant-sending village and a migrant receiving site in the global city of Hong Kong in order to describe the emergent place-subjectivity relations that arise within a mobile place.

\section{Going Global from the Rural - Al-Alinao Norte}

Al-Alinao Norte is an apposite example of a locality that has taken on a new and extended form. The village site of Al-Alinao Norte is in the foothills of the Philippine Cordillera Central, in the province of La Union on the northern island of Luzon. Village social and economic life is strongly shaped by the large numbers of female migrants circulating back and forth from Hong Kong. There are approximately 300 households (as counted by house in the provincial census), divided into four kin-based household clusters called sitios. Smallholder production of rice and tobacco has formed the basis of the traditional rural economy, supplemented with self-employed production of livestock, vegetables and services for the local market. To supplement inadequate local cash incomes, women began to look for short-term contracts as domestic workers overseas in the early 1970s. While women's migration is temporary in nature, individual female migrants have now spent up to twenty-five years away from the village on consecutive contracts abroad. Local NGO workers estimated that 85 per cent of households currently have at least one member overseas, the majority being female domestic workers in Hong Kong.

In the Al-Alinao Norte village site, impressive houses constructed with remitted earnings now sit amidst the rice fields. These houses are typically inhabited by men and children supported by wives and mothers working in Hong Kong. Frequently, the absent wife's mother has joined the household as overseer, while men have taken up 'feminine' tasks such as childcare and laundry. Outside the home, in an inversion of what people recognise as traditional gender roles, returned 
migrant women are running for 'masculine' positions in local government. In the fields, little tobacco is now grown, though men still farm a small selection of commercial crops, investing remittances in new technologies and varieties. Farmers no longer undertake much subsistence cultivation, but buy many of their daily needs in the market of nearby Naguilian town, the centre of their municipality.

People explained that they do not invest so much in the land because they are, 'waiting to go abroad' themselves. Many hope that the initial migration of women will lead to the relocation of the entire household overseas. Much of the village's economic activity is already 'abroad' - Al-Alinao Norte is developing what might be called an 'offshore' economy where cash changes hands in Hong Kong in payment for food and goods traded at home. Meanwhile, a small number of successful Hong Kong migrant workers have subsequently relocated their households to Australia and Britain. They employ kin as caretakers for their local interests and visit sporadically, yet remain active in community politics. These households have high local prestige, many residents expressing the hope that, with women taking successive contracts abroad, they, too, will be able to join their 'co-villagers' outside the Philippines.

Talking with respondents in the village site, it is evident that the places produced through this form of migrant translocality are not only located in economic and spatial terms, but in the social and affective dimensions of kinship and emotion. The subjectivities produced from this circulation are distinctly translocal, rather than more generally cosmopolitan. People imagine that going to Hong Kong or Australia or Britain will mean joining kin and village-mates dwelling and working there. They imagine a future where they will integrate themselves into the village networks that have already been extended in these sites. They are not reimagining themselves as 'cosmopolitans' or even Filipinos, rather they intend to become a new 'global' version of Naguiliano, their municipal-level identity. Thus Al-Alinao Norte's inhabitants don’t describe their place as 'scattered' or 'fragmented' but moving along specific nodes and pathways that reach around the globe. Those they claim as 'their' Naguiliano expatriates do not dwell in an abstract space of global flows, but in a new extension of home.

For migrants, contract work abroad entails periodic travel from home to worksite and back again. Regular circulation of such a large proportion of migrants back and forth from Hong Kong means that people can continue to engage physically in locality, locating their identities within social relations in Al-Alinao Norte and, more widely, Naguilian Municipality, while they are in Hong Kong. Along the routes taken by this circulation, new, multiple and layered subjectivities arise from movements through the various versions of place and localisation. In the following section, I sketch some of the sites of emplacement, and forms of localisation that migrants encounter in the extended, translocal version of Al-Alinao Norte. What I describe are key aspects of 
Lee and Li Puma's (2002) 'culture of circulation' - the practices of evaluation, constraint, consociality and resubjectivation that emerge with movements of people and exchanges of value and constitute new forms of place.

\section{Cultural Practices of Circulation}

In Al-Alinao Norte's village site, it seems there is always someone going 'abroad,' someone working there to receive them, and someone on the way back home to bring news, money and gifts that are put into community redistribution. Mobility between Hong Kong and Al-Alinao Norte creates subjects who imagine themselves circulating in a hyphenated community space (Al-Alinao Norte-Hong Kong). Their subjectivities are thus simultaneously place-based and global. To illustrate this point, I turn to an excerpt from an interview with an Al-Alinao Norte woman, Norma, recently returned from work in Hong Kong. Norma explained to me that she was weighing up the benefits of running for the position of councillor in the Municipal government or returning to Hong Kong on a new contract. When I asked her how she would feel about herself under each option, she said:

Now that I'm 'ex-Hong Kong', it's as if I'm a bigger person here than when I am there...

There I can provide more for my family; I am more to my friends. But when I'm there, I miss home. When I'm home, I miss being... the one I am there. There, all I can think about is home; home, all I think about is going back.

To contextualise Norma's comments, we need first to understand the experiences of the 'other end' of translocal Al-Alinao Norte - the equally translocal sites of Filipino community in Hong Kong.

As migrants in Hong Kong, women experience the conditions of their sojourn abroad as the intersection of Philippine state-sponsored and regulated work-abroad programs, working conditions in their employer's households, family ties and expectations and relationships with migrant consociates. Domestic work in Hong Kong commands some of the highest salaries available in the global market for migrant domestic labour. Filipino contract workers in Hong Kong typically live, as required by law, in their employers homes and the constraints and resubjectivations experienced by becoming a 'maid' in a live-in working relationship in Hong Kong have been described in detail by Nicole Constable (1997). Outside the workplace, Law's (2001) analysis of Filipinas in Hong Kong's public spaces points us toward the importance of relations between spaces, bodies and sensory practices in the constitution of locality as 'home-away-from-home.' Here, I build on her insights by exploring the micro-geographies of locality that are being reconstituted in and through the practices of Filipino translocalities in Hong Kong.

With current NGO estimates positing over 160,000 Filipino migrants working in Hong Kong, a suite of speciality services, both formal and informal, has developed to meet their needs for 
banking, shopping, socialising and finding 'a taste of home' (Law 2001). These services are centralised in the 'little Philippines' area of Central district, Hong Kong, in and around Worldwide Plaza shopping mall. The commercial tenants of 'Worldwide' offer banking, package-sending, telephone cards, telephones, mobile phone cards and Filipino food to eat in or take away. Nearby, churches, both Catholic (on Sundays) and the Filipino Iglesia ni Christo (Thursdays) offer worship and fellowship for the migrant Filipino community.

On Sundays, the informal and social aspects of the community erupt into the public space of Central. During the work week, Central is the business district of Kowloon. However, on Sunday, the 'off day' for the majority of (Catholic) Filipino workers, migrant workers converge on Statue Square and the neighbouring plaza area under the Hong Kong and Shanghai Bank building after attending church services. By taking over these public spaces, the Filipino migrants recreate the urban centre into a huge site of migrant consociality. Beginning mid-morning, the square and plaza and surrounding ferry terminal area become covered by small groups of Filipinas exchanging news, gossip, food and money. Women lay out blankets and newspaper in pre-arranged locations and wait to meet their friends and village mates. Hong Kong vendors sell them food and drink.

Commensality is a key aspect of this cultural reterritorialisation (Law 2001). Some women bring Filipino dishes they have purchased in the mall or prepared themselves in order to share with their friends.

This gathering - which my respondents simply referred to as 'Central'- has become an important time and space in Filipino culture and polity. NGOs representing migrant groups, Philippine municipal mayors looking for the overseas worker's vote, consular officials and researchers such as myself all visit women in the gathering. It is also the time when many workers communicate with their kin and friends in the Philippines. Mobile phones are ubiquitous in the cheerful melee of the Square. While few people take voice calls in the din, text messages are flying back and forth to the Philippines. Sundays are the day that many workers call home, organising the time by text message. Worldwide Plaza offers several long-distance calling services and women move back and forth from the square and plaza area to the phones and remittance services in the mall.

Sundays in Central materialise Appadurai's $(1995,1996)$ conception of translocality, recreating a series of mini-neighbourhoods from the migrant workers of sending villages from across the Philippine archipelago. Here, the overlapping of Filipino neighbourhoods onto the weekday spatial practices of Hong Kong's business district creates simultaneous and multiple versions of place (Law, 2001). Scholars theorising the urban are well aware of how such materialisations of circulation serve to produce the globality of urban centres (Liechty 1996; LiPuma \& Koelble, 2005). LiPuma and Koelble (p. 154) describe the global city as constituted by and constitutive of 
'multiple, transversal and reflexive circulations that are variously and provisionally stabilised'. This is certainly an apt description of Hong Kong, and Hong Kong's Sunday gatherings of Filipinos in Central embody this insight. 'Central' is organised into a kind of ethnopolitical map of the Philippines. During fieldwork in July, 2005, I found I could navigate through the throngs by asking women in the crowd for directions to the 'spot' or 'bus stop' occupied by particular language speakers, and from there establish locations for province of origin groups and, finally, municipal and village groups. Most of the women I asked directions from had a mental map of the regions and, within them, different localities that reconstituted themselves around the Central meeting place. While these groupings are not formally structured and have some fluidity, respondents assured me that each municipality and ethnic group have their 'bus stop' or 'area' which serves as their weekly meeting point. On these Sundays in Central, in the 'mini-Philippines' in Statue Square and the Hong Kong and Shanghai Bank Centre (HSBC), women from the Ilocano-speaking region of Northern Luzon, including Naguilian, put their newspaper and blankets under the HSBC building. When Appadurai predicted globalisation would allow new cultural formations to emerge on a 'landscape of group activity', he anticipated this new group would no longer be a 'familiar anthropological object, insofar as groups are no longer tightly territorialised, spatially bounded, historically unselfconscious, or culturally homogenous' (Appadurai 1996, p. 48). Some of these Hong Kong groups are, in fact, 'village groups' that do appear to define themselves on the basis of territoriality, shared history and cultural homogeneity, even if they are groups that coalesce spatially only periodically. Members of the groups understand themselves as extensions of the relations of sociality 'at home' as well as sites for the formation of new social relations in Hong Kong, and much of this consociality is mediated by mobile phone.

The kinds of circulations these groups embody - those that make Hong Kong into LiPuma and Koelble's (2005) vision of a 'global city' - are also redefining their sending village as locality. Here, Appadurai's 'trans' marks Lee and LiPuma's single and shared culture of circulation. The Sunday disruption of the cityscape by migrant workers and their self-locating practices of consociality make Central a material site for the reflexive practice of collective life (Ong and Collier 2005, p. 7) and constitute a node in this new culture of circulation. There are also another series of practices in the culture of circulation that are equally constitutive of translocality. These are the economic transfers that create new subject positions for migrants, as Norma suggested, above, as the benefactors of community and mainstays of households at home, increasing their status or, as in Norma's terms, making them 'more' at home. The next section sets out a series of practices that migrants deploy in order to remain part of their sending locality while abroad. Each of these economic practices allows migrants to remain within 'village-time' and deploy 'global' resources to meet local expectations of consociality and commensality in new ways. 


\section{Practices of Translocal Place-Making}

In the spatially-extended locality in Hong Kong, the co-presence necessary for Appadurai's (1995, 1996) vision of translocality is mediated by technologies, the most visible of which is the mobile phone. Migrants in Hong Kong text home to catch up on news from family and friends, arrange remittance of earnings, ask for reports on their investments at home and arrange voice calls. One of my Hong Kong respondents reports that she spends one sixth of her Hong Kong earnings on the mobile phone 'load' that allows her to stay in touch with home. That load is spent not just on calls to her eight year-old son, sister, parents and in-laws but also on calls to neighbours and friends. She regularly texts and calls the neighbours from whom she has purchased land and who are now working that land as tenants, as well as the carpenters she has contracted to renovate her house. Text messaging, for her, enables daily participation in 'home'.

The availability of Philippine phone services through Worldwide Plaza is an indication of the importance of the mobile phone to Filipino domestic workers in Hong Kong. Stores in the mall sell SIM cards and 'load' cards so migrants can communicate on Philippine networks. This reduces the costs of sending messages to Hong Kong for their family and friends at home, shifting the bulk of the charges to the migrant workers themselves. Worldwide Plaza retailers also sell 'load' that can be sent directly to phone services in the Philippines. This product enables migrants to fund incoming calls and messages from the Philippines directly, transferring the balance to their contact's Philippine phone account. Thus the mobile phone, as a technology with global reach, has been used to open up a new form of locality. Innovations in phone-mediated translocal consociality and economics continue to develop, in the service of what is now a rapidly expanding market.

In Al-Alinao Norte, respondents explained to me that the Central gathering is also a site where local-but-extra-national transactions take place. For example, when a migrant's family in the village site requires a pig to sacrifice for a particular ritual or cultural landmark - such as an engagement, wedding, or baptism - kin at home will negotiate the purchase price with their neighbours. Then, both families will text their migrant daughters or mothers to arrange for the migrants to exchange payment in Hong Kong. Eventually the equivalent value will either be deducted from the regular amounts remitted home or absorbed into generalised household reciprocity. This practice of long-distance payments shows how migrants overseas are texted-in to the everyday rituals of locality-building. Technology allows them to continue to participate in a day-by-day and fairly immediate way in Filipino village life. Pertierra (1992) describes these practices as working through what he calls a 'temporal structure of expectations' that builds and sustains trust between consociates and kin and produces locality. He argues that it is through regular dealings and a common pool of shared experiences that people constitute a common local 
world. With global mobility and mobile phone technology, texting daily and calling weekly allow migrants to remain, at least partially, within the 'village-time' Pertierra describes. Technology allows them to both catch up with and contribute to their sending community. While migrants may be at some remove from one set of local experiences, their economic contributions allow them to build and sustain trust within their locality.

Regular economic transfers directly to Philippine households are the most common mode of economic support. One Hong Kong respondent explained to me that she sent her household mother, father, single younger sister, and her own two sons - a monthly 'household allowance' of PHP7000 from her HK $\$ 3680$ salary via bank transfer. ${ }^{1}$ She sends a text message once she has processed the transfer and her sister then travels to the nearest bank branch to pick up the cash. Her family use the money for regular expenses such as electricity bills, rice purchases, transport costs, cooperative fees, school fees, clothing, health care and children's allowances. While bank-to-bank transfer is her preferred method of sending cash back to the Philippines, other migrants use specialised financial and remittance agencies and informal channels, usually friends and villagemates going home on vacation. These remittance agencies occupy an interesting niche in the migrant services market. In Hong Kong, many remittance agencies offer benefits such as 'free' text messaging cards or phone call cards and confirmation by text message that a remittance has been paid out in the Philippines. TMT, for example, offers a transaction fee discount, a 'free' phone card and text message confirming pick-up. With 30 million mobile phone users (and only 16.4 million ATM cardholders), mobile phone based remittance and remittance advice is the path of choice. Another company, Philippines-based Globe, has set up G-cash, a service that takes this idea one step farther. G-cash sells migrants 'cash' cards that then allow them to transfer balances to other Globe mobile service subscribers. This transferred value can only be spent at certain government agencies or businesses - bookstores, pharmacies etc. The product is designed to allow migrants more control over the way that recipients in the Philippines spend the monies they remit. In AlAlinao Norte, I heard a rumour that migrants were selling P100 G-cash cards for P200 in the Central Sunday gathering. I could not verify this with any of my Hong Kong respondents, but the idea reveals some of the deep anxieties that underpin practices in this culture of circulation.

Migrants have good reason, it appears, to wish to constrain the consumption enabled by the monies they earn and send home. Comparing notes on remittances and investments at the Sunday gathering in Central lets migrants evaluate their relationships, both social and economic, with their sending households and communities.

Another important practice in the material culture that comes with circulation is the balikbayan box. This is a large package of goods shipped home as gifts for family and friends that serves as a supplementary technology for maintaining social relations and meeting expectations in sending 
households and villages. 'Balikbayan boxes' contain household goods, packaged food, cosmetics, personal items and clothes that will be distributed by the women's sending household within their home communities (Rafael 1997; Szanton Blanc 1996). The practice of sending boxes home is now so ubiquitous across the Filipino diaspora that the Philippine media describes the contents of boxes as 'typical' - 'the usual stuff overseas workers send' (Sotelo-Fuertes 2003). In Central, a series of storefronts on the top floor of Worldwide Plaza offer door-to-door shipping of these boxes to the Philippines. Here women store and pack the goods they have collected. The contents spilling out of these bags and boxes appear to be quite literally the stuff of daily life at home. Staples such as tinned meat, jam, coffee, milk drinks and biscuits are sent in bulk, in containers intended for longterm storage, perhaps as food security for times of emergency. Much of the packaging can be used for storage when the product has been consumed. The added cost of shipping these goods actually seems to undermine any savings on the items sent as compared to their purchase prices in the Philippines (McKay 2004). And most of the things sent home are not 'souvenirs' of the new global space of Hong Kong, but replace items that women would have bought for daily domestic life at home. Though some of the objects, like cosmetics, no doubt tell stories about migration, cosmopolitan spaces, and social and cultural identities, the bulk of the boxes contain 'bulk items' preserved food, towels, soap, and linens - things which speak about sustaining households and quotidian living. This translocal practice of sending gifts reproduces migrants' domestic identities at home. By giving items for daily use, migrants remind their households of their long distance affections and constitute, in a material way, their own household participation.

The sense of immediacy engendered by texting, phone calls and boxes is critical in sustaining locality. Immediate responses to crises at home on the part of workers abroad further strengthen translocal trust and intimacy. Securing financial aid in a household or community emergency has great potential to enhance a migrant's status. Text messages and calls received by migrants often convey requests for emergency finance to cover the expenses of school fees, weddings, funerals, unexpected medical expenses and livelihood emergencies. Such requests are a significant constraint on migrants' own abilities to save their Hong Kong earnings for future investment. Unanticipated requests, especially for large amounts, often entail migrants negotiating loans against their future salaries in the credit agencies around Central. When they have exhausted this resource, they can turn to their employers for advances or borrow additional funds from other migrants who have savings in the bank. Demand for loans to be sent back to the Philippines has created a secondary market for credit in the Filipino community where women borrow from credit agencies, then reloan the money to other Filipinas at higher rates of interest.

Lastly, the locality-based groups of migrants who meet each week in Central often organise themselves to 'give back' to their communities at a group level. Once example is that of 
Naguilianos sa Hong Kong, an organization that includes many migrants from Al-Alinao Norte. This group started a savings plan with the long-term goal of donating funds to the Naguilian municipal government. After almost a decade of saving, the group funded the construction of a new building beside the Municipal Hall - the Overseas Workers Building. In co-operation with the municipal government and a local NGO, they envision that this building will serve as a resource and service centre for departing migrants, vacationing overseas workers, returnees and their families. The plan is for it to offer counselling for returned workers and long-distance households, as well as skills training and small-enterprise development workshops.

\section{Revisiting Locality under Globalisation}

This case study has outlined the social and material practices in the culture of circulation of AlAlinao Norte-Hong Kong. To see how this might point us towards new ways to approach locality through ethnographic methodologies, I want to revisit the kinds of theoretical frames through which we might understand transformations of place and locality.

If we were to draw on Massey's (1994) concept of 'extraverted place' we would expect to see boundaries dissolving as cultural influences, communications media and economic investment increasingly cross places. This insight is one consonant with a widespread economistic discourse of globalisation as a homogenising process. In what is now a classic example of this discourse, Manuel Castells (2000, pp. 458-9) writes:

Thus, people do still live in places. But because function and power in our societies are organised in the space of flows, the structural domination of its logic essentially alters the meaning and dynamics of place. Experience, by being related to places, becomes abstracted from power, and meaning is increasingly separated from knowledge... The dominant tendency is toward a horizon of networked, ahistorical spaces of flows, aiming at imposing its logic over scattered, segmented places.

For Castells, power lies in the ability to broker relationships across the boundaries between the inside of a locality and the outside of 'the world' thus claiming the (singular) site of circulation (Kelly 2000, p. 14). In this view, the fracturing of boundaries and borders leads to local powerlessness against global flows. But local powerlessness against the global does not give us an accurate representation of the practices of place-making and locality produced by circular migration from Al-Alinao Norte. The boundaries of the village and Naguilian municipality do not appear, at least in the experience of my respondents, to have become blurred. Nor are people describing lives lived in a scattered or segmented place. The power they can enact in the Philippines in terms of creating comfortable livelihoods and new social services relies directly on their intimate, quotidian 
connections with individuals and groups in the extended locality in Hong Kong. Hong Kong is not the 'outside' of Al-Alinao Norte but hosts an extension of it. In this understanding, there is no single 'site' of circulation over which to lay claim because circulation is a process with its own culture, rather than a singular spatial referent.

In this literature on global flows much is said about subject positions and the 'politics of location', but little attention is given to the locatedness or mobility of subjectivities. This omission leads to what seem to be some strange dictates for subjectivity: thinking about indigenous peoples in diaspora. Dirlik (2001, p. 8) argues that 'ethnics' are caught in between 'placing' or 'deterritorialising' themselves - either becoming part of the places in which they are located or identifying with cultural nationalisms. Offering this choice as a binary either/or refuses the option of a both/and or the plurality of other identity processes that might lead to radically different modes of becoming. Yet is it not possible to identify yourself almost simultaneously as both a local and a national? Behind both these binaries is the conception of identity as a 'politics of place' that must necessarily lock one into a singular locality. Appadurai (1990) earlier predicted a deterritorialisation of culture where experience is mediated by complex and abstract structures located elsewhere, a claim recently taken up by the contributors to Ong and Collier (2005). My data suggest, however, that mobility can, in fact, recreate elsewhere as a part of 'home' through the reterritorialisation of locality in its extension into a global world. Thus, while migrants may signal the deterritorialisation of their sending place, the practices of translocal place-making I have outlined here do not provide evidence for a deterritorialisation of culture.

In translocal Al-Alinao Norte we see that the abstract 'broader social networks' envisioned by Massey and Castells are actually held, transformed and even produced not at the level of place, but at the level of subjectivity that emerges from the place-based relations. Thus locality in its material, social, and affective forms constitutes distinctive subjects and subjectivities, acting as what Deleuze and Guattari would call a 'line of deterritorialisation' in global flows. Translocality, as it emerges in Central, Hong Kong, and in sending villages is a 'positive reterritorialisation' where culture and social relations are recuperated and refigured, rather than lost. The large Sunday gathering of Filipinas in Central de- and reterritorialises locality in two ways: Firstly, the presence of Filipinas in Central disrupts and dislocates Hong Kong territoriality (see Law, 2001). Secondly, this site of disruption clears a space where the localities of municipalities and villages can reconfigure, reterritorialising themselves both in extension and 'at home' in the Philippines.

To approach these experiences of multiple de and re-territorialisations of locality, we need theorisations of subjectivities and their constitution through affective and embodied experiences. We need to theorise subjectivity-place relations as, in fact, extending and reworking countless places. The intensities of globalisation now mean that almost all places now have distinctively local 
subjectivities that are constituted in part through the (sometimes vicarious) mobility experiences of kin and consociates. This means that ethnographers studying the new spaces of flows find new forms of locality emerging both through and within them. With these, they find new forms of power and agency as well as older versions.

For an example of this, we can return to Norma's comments, above. Here, she describes a subjectivity that is, following Braidotti (1998) inherently nomadic - moving within and between a fluid series of subject positions, dwelling in them, identifying from them in multiple and sometimes contradictory ways, but never completely determined by one subject position. Moving between the village and Hong Kong, Norma occupies multiple place-times and inhabits a simultaneity of complex and multi-layered identities, all mobile. While places and subjects are mutually constitutive, subjectivities are of another order - they transcend the materialities of place because they are formed in movement and through identification or disidentification with multiple, complex and simultaneously overlapping localities. Thus Norma is 'more' here, at home, when she is 'there', away in Hong Kong - she situates herself as a subject in an extended form of locality, moving her self-understanding between multiple spaces of subjection. Norma describes this with an embodied metaphor of size - being bigger in one place when she is physically in another. She also identifies herself, as do her village consociates, as an 'ex-Hong Kong,' an identity that marks her as doubly displaced.

Norma is at once a worker, household member and friend, she negotiates her subjections with both affect and economy, sending packages, money and 'help' back home in a way that increases her status there while assuaging her sense of diminishment as a 'displaced' domestic labourer abroad. Technology, through the ensemble of remittances and text messages, allows her to both inhabit and create the multiple space-times this new subjectivity requires. The kind of intimate economics at work here produces new distanciated dimensions of affect which characterise this new form of locality. Instead of 'shattered' places resulting from global mobility, Norma shows us how the pragmatics of maintaining locality suggest that it is taking on new, specific and increasingly heterogenous forms. Instead of the annihilation of place by space that might be expected with globalisation, we find adaptations, reterritorialisations and multiplied sense of simultaneous place-times, constitutive of and constituted through this mobile subjectivity. The new subjectivity-locality relation that emerges here, however, seems to impel continued circulation between the poles of translocality, in an attempt to mediate the very real differences in subjections experienced between the two places. 


\section{Acknowledgements}

Thanks to my respondents in the Philippines and Hong Kong for sharing their experiences and my colleagues at University of the Philippines, Baguio, for their continued support and hospitality. My co-presenters in the 2004 Australian Anthropological Society meetings and colleagues Monique Skidmore and Benjamin Smith provided helpful comments on earlier drafts of this paper. At ANU, Sandra Davenport assisted with formatting and referencing. All errors of fact and interpretation remain my own.

\section{Notes}

[1] At the time of my research (July, 2005) $1 \mathrm{HKD}=\mathrm{PHP} 7.40 / 1 ; \mathrm{AUD}=5.8 \mathrm{HKD}$

\section{References}

Appadurai, A. (1990) 'Disjunction and difference in the global cultural economy', in Global Culture: Nationalism, Globalisation and Modernity, ed. J. Featherstone, Sage, London, pp. 295-310.

Appadurai, A. (1995) 'The production of locality', in Counterworks: Managing the Diversity of Knowledge, ed. R. Fardon, Routledge, New York, pp. 204-225.

Appadurai, A. (1996) Modernity at Large: Cultural Dimensions of Globalisation, University of Minnesota Press, Minneapolis.

Bello, W. (2005) 'Afterthoughts: the end of People Power?' The Nation, October 31, 2005, New York, Available at http://news.inq7.net/viewpoints/index.php?index=2\&story_id=54534\&col=65 (Accessed October 31, 2005).

Boyle, P. (2002) 'Population geography: transnational women on the move', Progress in Human Geography, vol. 26, no. 4, pp. 531-543.

Braidotti, R. (1998) 'Difference, diversity and nomadic subjectivity'. Available at http://www.let.uu.nl/ Rosi.Braidotti/personal/rosilecture.html (Accessed 14/11/2001).

Castells, M. (2000) The Rise of the Network Society, Blackwell, Oxford, UK.

Constable, N. (1997) Maid to Order in Hong Kong: Stories of Filipina Workers, Cornell University Press, Ithaca.

Constable, N. (2003a) 'A transnational perspective on divorce and marriage: Filipina wives and workers', Identities: Global Studies in Culture and Power, vol. 10, no. 2, pp. 163-180.

Constable, N. (2003b) Romance on a Global Stage: Pen Pals, Virtual Ethnography and 'Mail Order' Marriages, University of California Press, Berkeley. 
Dirlik, A. (2001) 'Placed-based imagination: globalism and the politics of place', in Places and Politics in an Age of Globalisation, eds. R. Prazniak \& A. Dirlik, Rowman and Littlefield, New York, pp. 15-51.

Deleuze, G. \& Guattari, F. (1987) A Thousand Plateaus: Capitalism and Schizophrenia, trans. B. Massumi, University of Minnesota Press, Minneapolis.

Kelly, P. (2000) Landscapes of Globalisation: Human Geographies of Economic Change in the Philippines, Routledge, London.

Lan, P-C. (2003) 'Maid or Madam? Filipina migrant workers and the continuity of domestic labour', Gender and Society, vol. 17, no. 2, pp. 187-208.

Law, L. (2001) 'Home cooking: Filipino women and geographies of the senses in Hong Kong', Ecumene, vol. 8, no.3, pp. 264-283.

Lee, B. \& LiPuma, E. (2002) 'Cultures of circulation: the imaginations of modernity', Public Culture, vol. 14, no. 1, pp. 191-213.

Liechty, M. (1996) 'Kathmandu as translocality: multiple places in a Nepali Space', in The Geography of Identity, ed. P. Yaeger, University of Michigan Press, Ann Arbour.

LiPuma, E. \& Koelble, T. (2005) 'Cultures of circulation and the urban imaginary: Miami as example and exemplar', Public Culture, vol. 17, no.1, pp. 153-179.

Massey, D. (1994) Space, Place and Gender. Polity Press, Cambridge.

McKay, D (2004) 'Everyday places - Philippine place-making and the translocal quotidian', Proceedings of the Cultural Studies Association of Australasia (CSAA) Conference, Everyday Transformations The Twenty-First Century Quotidian, $9^{\text {th }}-11$ th December, Murdoch University.

McKay, D (2005) 'Reading remittance landscapes: female migration and agricultural transition in the Philippines', Danish Journal of Geography, vol. 105, no.1, pp. 89-99.

Ong, A. \& Collier, S. eds (2005) Global Assemblages: Technology, Politics and Ethics as Anthropological Problems, Blackwell Publishers, Oxford and Malden.

Opiniano, J. (2003) 'Maximising the benefits of OFW remittances', Inquirer News Service, Available at http://www.inq7.net/globalnation/sec_rec/2003/may/16-01.htm (Accessed 27 January 2004).

Pertierra, R. (1992) 'Trust and the temporal structure of expectations in a Philippine village', The Australian Journal of Anthropology, vol. 3, no. 3, pp. 201-217.

Pertierra, R. (2001) 'Multiple identities, overseas labour and a disaporal consciousness in a local community', in Going Global: Asian Societies on the Cusp of Change, ed A. Malay, Jnr., Asian Centre, University of the Philippines, Manila, pp. 74-91. 
Pertierra, R., Ugarte, E.F., Pinggol, A., Hernandez, J., \& Dacanay, N.L. (2002) Txt-ing Selves: Cellphones and Philippine Modernity, De La Salle University Press, Manila.

Pertierra, R. ed., with M. Cabilao, M. Escobar \& A. Pinggol, (1992) Remittances and Returnees: the Cultural Economy of Migration in Ilocos, New Day Publishers, Quezon City.

POEA, Philippine Overseas Employment Agency (2004), Available at http://www.poea.gov.ph/html/statistics.html (Accessed 06 October, 2004).

Puri, S. \& Ritzema, T. (1999) 'Migrant worker remittances, micro-finance and the informal economy: prospects and issues', Working Paper No 21, International Labour Office, Geneva.

Rafael, V. (1997) 'Your grief is our gossip: overseas Filipinos and other spectral presences', Public Culture, vol. 9, no. 2, pp. 267-291.

Rodriguez, E. (1998) 'International migration and income distribution in the Philippines', Economic Development and Cultural Change, vol. 46, no. 2, pp. 329-350.

Sotelo-Fuertes, Y. (2003) 'AC's 2nd homecoming was her last', Inquirer News Service, Available at http://www.inq7.net/nat/2003/apr/24/nat 13-1.htm (Accessed 24 April, 2004).

Szanton-Blanc, C. (1996) 'Balikbayan: a Filipino extension of the national imaginary and of state boundaries', Philippine Sociological Review, vol. 44, nos. 1-4, pp. 178-193.

Tyner, J. \& Donaldson, D. (1999) 'The geography of Philippine international labour migration fields', Asia Pacific Viewpoint, vol. 40, no. 3, pp. 217-234. 